\title{
Arbovirus Models to Provide Practical Management Tools for Mosquito Control and Disease Prevention in the Northern Territory, Australia
}

Author(s): Susan P. Jacups, Peter I. Whelan, and David Harley

Source: Journal of Medical Entomology, 48(2):453-460. 2011.

Published By: Entomological Society of America

DOI: http://dx.doi.org/10.1603/ME10193

URL: http://www.bioone.org/doi/full/10.1603/ME10193

BioOne (www.bioone.org) is a nonprofit, online aggregation of core research in the biological, ecological, and environmental sciences. BioOne provides a sustainable online platform for over 170 journals and books published by nonprofit societies, associations, museums, institutions, and presses.

Your use of this PDF, the BioOne Web site, and all posted and associated content indicates your acceptance of BioOne's Terms of Use, available at www.bioone.org/page/terms_of_use.

Usage of BioOne content is strictly limited to personal, educational, and non-commercial use. Commercial inquiries or rights and permissions requests should be directed to the individual publisher as copyright holder. 


\title{
Arbovirus Models to Provide Practical Management Tools for Mosquito Control and Disease Prevention in the Northern Territory, Australia
}

\author{
SUSAN P. JACUPS, ${ }^{1}$ PETER I. WHELAN,${ }^{2}$ AND DAVID HARLEY ${ }^{3}$
}

\begin{abstract}
J. Med. Entomol. 48(2): 453-460 (2011); DOI: 10.1603/ME10193
ABSTRACT Ross River virus (RRV) causes the most common human arbovirus disease in Australia. Although the disease is nonfatal, the associated arthritis and postinfection fatigue can be debilitating for many months, impacting on workforce participation. We sought to create an early-warning system to notify of approaching RRV disease outbreak conditions for major townships in the Northern Territory. By applying a logistic regression model to meteorologic factors, including rainfall, a postestimation analysis of sensitivity and specificity can create rainfall cut-points. These rainfall cut-points indicate the rainfall level above which previous epidemic conditions have occurred. Furthermore, rainfall cut-points indirectly adjust for vertebrate host data from the agile wallaby (Macropus agilis) as the life cycle of the agile wallaby is intricately meshed with the wet season. Once generated, cut-points can thus be used prospectively to allow timely implementation of larval survey and control measures and public health warnings to preemptively reduce RRV disease incidence. Cut-points are location specific and have the capacity to replace previously used models, which require data management and input, and rarely provide timely notification for vector control requirements and public health warnings. These methods can be adapted for use elsewhere.
\end{abstract}

KEY WORDS mosquito control, arbovirus, Ross River virus, mosquito-borne disease, modeling

Ross River virus (RRV) is a mosquito-borne virus that requires a vertebrate host to complete its life cycle, and so by definition is a zoonosis. The primary vectors in the Northern Territory (NT) of Australia are the northern salt-marsh mosquito Aedes vigilax (Skuse) and the common banded mosquito Culex annulirostris (Skuse) (Whelan 1987, 1989; Russell 2002; Whelan et al. 2006; Kurucz et al. 2009a). The virus is thought to be maintained primarily by enzootic cycles, although it may be maintained in some localities by transovarial transmission (Lindsay et al. 1993, Russell 2002). The most commonly implicated reservoir hosts are marsupials (Kay et al. 1982, Russell 1994). Marsupials provide the best disease amplification, with humans considered poor amplifiers, and are usually regarded as dead-end hosts in the cycle (Kay et al. 1982, Russell 1994). It has been speculated that RRV and Barmah Forest virus are evolutionally linked with marsupials. This explains the restriction of these viruses to Australia and Papua New Guinea, where there are many endemic marsupial species (Kay et al. 1982, Lindsay et al. 1995). Serological studies indicate that marsupials are commonly infected with RRV, and macropods

\footnotetext{
${ }^{1}$ Corresponding author: School for Environmental Research, Institute of Advanced Studies, Charles Darwin University, Darwin, Northern Territory, 0909, Australia (e-mail: Susan.Jacups@cdu.edu.au).

${ }^{2}$ Medical Entomology, Centre for Disease Control, Northern Territory Department of Health and Families, Darwin, NT, Australia.

${ }^{3}$ National Centre for Epidemiology \& Population Health, College of Medicine, Biology \& Environment, Australian National University, ACT, Australia.
}

(kangaroos and wallabies) are known to be major reservoirs (Doherty et al. 1971). This link between marsupials and RRV is consistent with the failure of RRV to establish outside this region after the 1979 Western Pacific epidemic (Mackenzie et al. 1998).

RRV disease is the most geographically widespread and frequently occurring arboviral disease in Australia, with up to 4,800 cases reported in some years (Communicable Diseases Australia 2006). In humans RRV disease is nonfatal, with minor symptoms such as the following: rash, fever, arthritis, arthralgia, myalgia, general weakness, and fatigue (Flexman et al. 1998, Harley et al. 2002, Jacups et al. 2008a). Although the symptoms of RRV infection are mild, the arthritis and fatigue can be debilitating for 3-6 mo, with postinfection fatigue further affecting a minority of cases (12\%) (Hickie et al. 2006). This disease is of economic concern because RRV infections occur most commonly in 30-34 yr olds, a critical age group for workforce participation (Jacups et al. 2008b). Financial costing from a 1997-1999 Australian cohort estimated $\$ 1,018$ (Australian currency) per patient averaged across all severity levels. Calculations by others indicate that annual costs to the Australian health system amount to more than $\$ 10$ million (United States currency) in direct medical costs, with millions more spent on mosquito control (Aaskov et al. 1998, Harley et al. 2001). Mechanisms for surveillance and control of RRV transmission include surveillance of human cases, monitoring of mosquito vectors, surveillance of meteorological conditions, timely and targeted vector 
control, and public health warnings, sometimes with the aid of predictive models (Whelan et al. 1997, Jacups et al. 2008a).

Predictive early-warning models have been produced for RRV infections for different regions in Australia, including locations in the wet-dry tropics such as Darwin, NT (Jacups et al. 2008a). The creation of a regionally-specific predictive model for RRV epidemics can guide public health interventions, such as the timing of media releases, which notify the public to minimize vector attack by the use of protective clothing and repellents and the avoidance of high mosquito-density habitats. However, models require maintenance, collecting, cleaning, and imputing of data, as well as staff training. The South Australianbased RRForcastor requires the input of the predicted rainfall using Bureau of Meteorology three monthly outlooks for the preceding $3 \mathrm{mo}$ as a proportion of the historic mean for each region (Williams et al. 2007, 2009). Queensland Health has introduced the VectorBorne Disease Early Detection and Surveillance System, designed to provide public health officials (secure log-in required) with decision-support tool to assist with the management of mosquito-borne disease. By mapping weekly counts of RRV infection by Local Government Area against a threshold (algorithm not given), it provides public health officials with access to disease data for RRV and Barmah Forest virus in Queensland (Queensland Institute of Medical Research 2010). The model for Darwin requires counts of three mosquito species, plus total rainfall from the preceding month and the average minimum monthly temperature from the preceding 3 mo (Jacups et al. 2008b). Moreover, the timeliness of predictive models is usually limited; as such early-warning systems notify the public to avoid mosquito attack, but rarely can models provide timely notification for mosquito control. Conditions for RRV disease epidemics are commonly signaled by peak numbers of adult vector mosquitoes or disease cases, by which time mosquito larval control efforts are redundant. Broad area vector adulticiding is not considered practical or effective in the Darwin area because of the short duration of effective control, the potential impact on nontarget organisms, and the inability of aerosol fogs to penetrate thick vegetation. Once adult mosquitoes are abundant, larviciding is no longer practical or effective. Public health professionals are then left with media releases and public warnings as the only preventative measures to reduce the infection rate from this debilitating disease.

Meteorological factors, especially rainfall and temperature, are established drivers of arboviral epidemics (Tong and Hu 2001, Day and Shaman 2008). For instance, exceptionally high rainfall coincided with all major regional Rift Valley fever epidemics in Kenya since 1951 (Linthicum et al. 1999). Summer rainfall is associated with Murray Valley encephalitis seroconversion in chickens, with a cut-point (threshold) of $>100 \mathrm{~mm}$ rain for Alice Springs, and $>400 \mathrm{~mm}$ for Tennant Creek (Whelan et al. 2003). Furthermore, the analysis of Australian RRV epidemics between

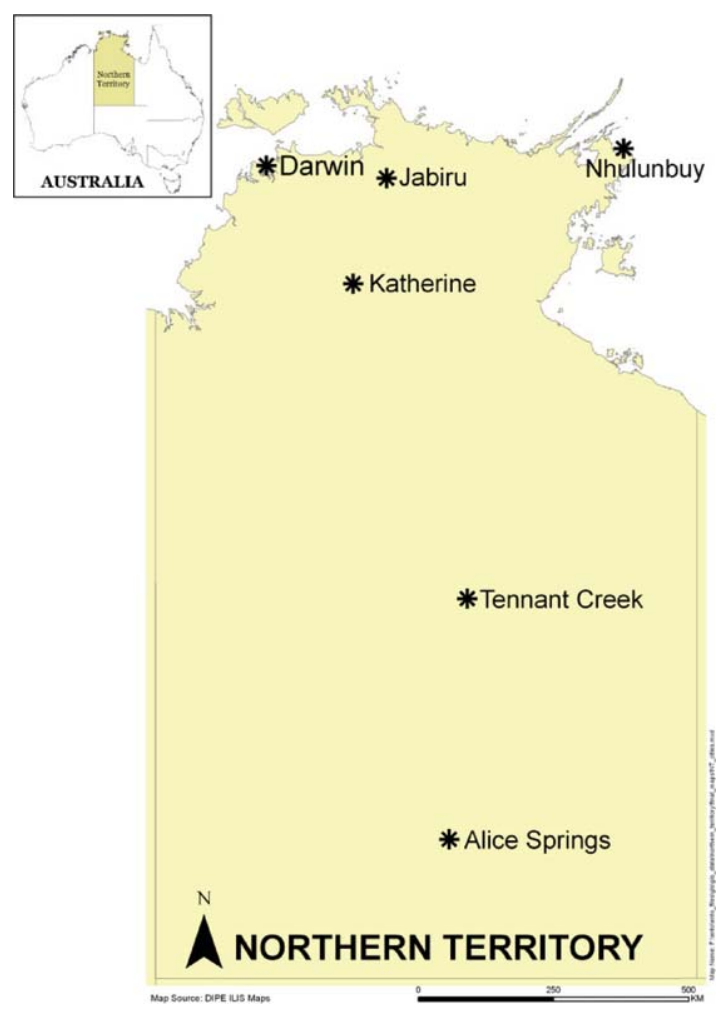

Fig. 1. Major townships in the NT with adult mosquito monitoring programs. (Online figure in color.)

1886 and 1998 showed above average rainfall commonly preceded RRV epidemics (Kelly-Hope et al. 2004, Williams et al. 2009). Epstein reports the importance of weather parameters in projecting conditions conducive to disease epidemics (Epstein 1999). Knowledge of disease/environmental associations is essential for predicting and responding to weatherrelated increases in RRV incidence.

The Medical Entomology (ME) unit of the Department of Health and Families, NT, currently monitors vector mosquito populations in the major NT towns (Fig. 1) using adult mosquito encephalitis vector surveillance traps (Rohe and Fall 1979). To reduce the risk of arboviral disease transmission and nuisance mosquito biting to Darwin residents, helicopter-assisted larval surveys guide ME mosquito larval control efforts, specifically for Ae. vigilax and $C x$. annulirostris (Whelan 1987, 1989; Russell 2002; Whelan et al. 2006; Kurucz et al. 2009a). Aerial surveys and control operations are expensive and labor intensive, usually conducted by three ME staff who survey pooled water and indicator sites by helicopter, landing frequently to sample mosquito larvae (Kurucz et al. 2009a). Aerial larval control operations are rarely performed outside the Darwin urban area proximity, although ground operations (on quad bikes) and control are routinely performed, sometimes in cooperation with other landholders in the urban and peri-urban areas where helicopter operations are impractical. 


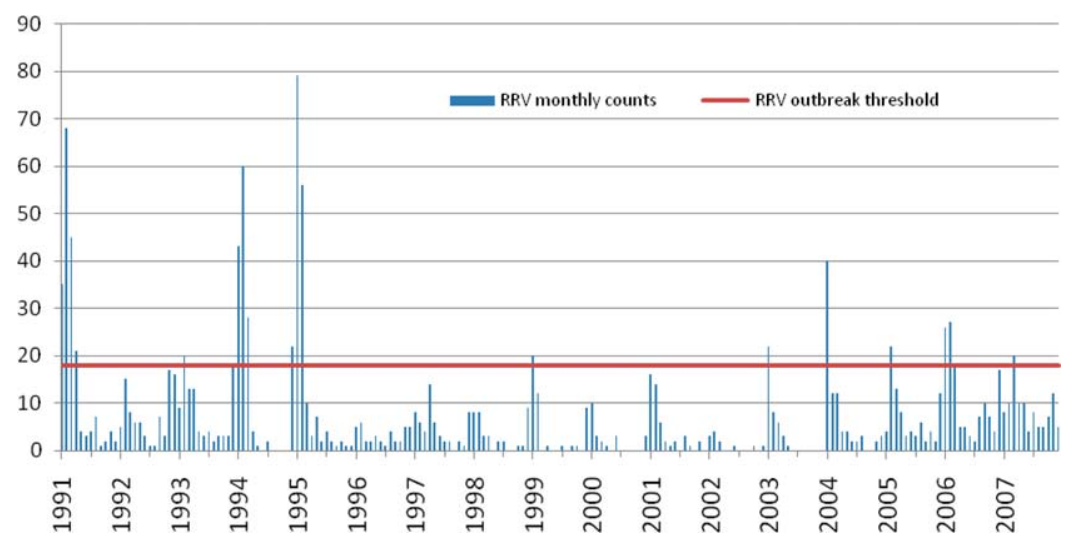

Fig. 2. Monthly Darwin RRV counts with RRV outbreak threshold. (Online figure in color.)

We sought to create a management tool, not just an early-warning system, to improve ME's intensive mosquito larval operations by providing timely advisories for vector control. We have addressed this problem by applying sensitivity and specificity cut-points from logistic regression postestimation methods. This method has previously been used as an epidemiological tool for health risks (Bruzzi et al. 1985) and to generate malaria parasitemia cut-points for diagnosing clinical malaria (Smith et al. 1994, Tjitra 2001). Applying these methods to a logistic regression for RRV epidemic conditions, including the variable "total cumulative rainfall during the preceding month," allows a sensitivity and specificity analysis that determines the rainfall cut-point above which previous RRV epidemics have occurred, specific to each township in the NT. These rainfall cut-points can then prospectively act as simple early-warning systems that notify of potential RRV epidemic conditions across the NT. When used in Darwin, these cut-points provide ME with a management tool to deliver an earlier indicator or RRV outbreaks than previously used models, and to indicate timing for priority vector control to decrease the risk of RRV disease epidemics. For the other major townships in the NT where vector control measures are rarely undertaken, cut-points provide early notification of disease risk to assist public health warnings.

Woodruff et al. (2006) found that preconditions for an epidemic in temperate Western Australia were established by November; meteorologic conditions after November did not determine the occurrence of epidemics, although conditions in later months influenced epidemic scale. In the NT and Queensland, January and February are peak months for RRV notifications (Gatton et al. 2005), whereas the critical months for establishing ecological epidemic conditions are just before the start of the RRV disease season in the September to November period (Whelan et al. 1997). Furthermore, larval control is less relevant later in the wet season (December-April) when the tidally influenced wetlands become seasonally flooded, creating the opportunity for larval predation by fish, and offering fewer sites for salt-marsh mosquito oviposition. We thus assessed December and January rainfall, as these months have historically been associated with establishing epidemic conditions (Whelan et al. 1997).

\section{Materials and Methods}

Case Data. Laboratory-confirmed cases of RRV infections notified to the arbovirus disease surveillance program of the Northern Territory Centre for Disease Control during the 17 yr between 1 January 1991 and 31 December 2007 (204 mo) were included. Data were provided by NT Centre for Disease Control as monthly counts for all six major towns in the NT. Woodruff et al. (2002) defined "RRV outbreak" or "RRV epidemic" as any financial year in which the number of cases exceeded the mean plus 1 standard deviation during the study period (Fig. 2). We analyzed climatic and disease variables at a monthly time scale and thus defined an epidemic month as a calendar month in which the number of cases exceeded the monthly mean plus 1 standard deviation (rounded to the nearest integer) for the 17-yr study period. This study was approved by the Joint Human Ethics Committee of the Northern Territory Department of Health and Families, and Menzies School of Health Research, approval number 06/28.

Meteorologic Data. Daily rainfall, daily temperature (minimum, maximum, mean daily), humidity (minimum, maximum, mean daily), and tidal (sea level) data were provided by the Australian Bureau of Meteorology for each of the relevant NT townships throughout the study period. To identify the most strongly associated variables for each predictive model, meteorological data were cumulated or averaged, with lag times applied for up to $3 \mathrm{mo}$ (Jacups et al. 2008b). Tide was only included in models of coastal or subcoastal townships (Jabiru has tidally influenced river systems within saltmarsh mosquito flight range).

Statistics. Correlations were used to examine meteorological associations with RRV epidemics for each of the major townships in the NT. The best fit of each meteorological variable (or derivative) most strongly associated with RRV epidemics was then included in multivariate logistic regression models, 
Table 1. The association of rainfall and RRV epidemics, NT

\begin{tabular}{llll}
\hline \hline \multirow{2}{*}{ Exposure } & \multicolumn{2}{c}{ Disease epidemic } & \\
\cline { 2 - 3 } & $\begin{array}{c}\text { RRV epidemic } \\
\text { month }\end{array}$ & \multicolumn{1}{c}{$\begin{array}{c}\text { RRV nonepidemic } \\
\text { month }\end{array}$} & Totals \\
\hline Rainfall $>\mathrm{c}$ & $\mathrm{n}_{\mathrm{c}} \lambda_{\mathrm{c}}$ & $\mathrm{n}_{\mathrm{c}}\left(1-\lambda_{\mathrm{c}}\right)$ & \\
Rainfall $\leq \mathrm{c}$ & $\mathrm{N} \lambda-\mathrm{n}_{\mathrm{c}} \lambda_{\mathrm{c}}$ & $\mathrm{N}(1-\lambda)-\mathrm{n}_{\mathrm{c}}\left(1-\lambda_{\mathrm{c})}\right.$ & $\mathrm{n}$ \\
Totals & $\mathrm{N} \lambda$ & $\mathrm{N}-\mathrm{n}_{\mathrm{c}}$ \\
& $\mathrm{N}(1-\lambda)$ & $\mathrm{N}$ \\
\hline
\end{tabular}

fitted for parsimony. Coefficients with errors and 95\% confidence intervals (Smith et al. 1994, Woodruff et al. 2002) were generated as previously verified, using a multivariate logistic regression model in the form of the following:

$$
\log (\mathrm{P} /[1-\mathrm{P}])=\alpha+\beta_{1} \mathrm{x}_{1}+\beta_{2} \mathrm{x}_{2}+\ldots+\beta_{\mathrm{n}} \mathrm{x}_{\mathrm{n}}
$$

Where $\mathrm{P}$ is the probability of an epidemic, $\mathrm{x}_{1}$ are meteorological variables specific to each township, and $\alpha, \beta_{1 \ldots \mathrm{n}}$ are constants estimated from the data. As previously verified and published, the following formulae were used to estimate sensitivity and specificity of RRV epidemic definition (Table 1) (Smith et al. 1994, Tjitra 2001):

$$
\begin{gathered}
\text { Sensitivity }=\left(\mathrm{n}_{\mathrm{c}} \lambda_{\mathrm{c}}\right) /(\mathrm{N} \lambda) \\
\text { Specificity }=1-\mathrm{n}_{\mathrm{c}}\left(1-\lambda_{\mathrm{c}}\right) / \mathrm{N}(1-\lambda)
\end{gathered}
$$

Positive predictive value $(\mathrm{PPV})=\mathrm{n}_{\mathrm{c}} \lambda_{\mathrm{c}} / \mathrm{n}_{\mathrm{c}}=\lambda_{\mathrm{c}}$

Where c represents the rainfall cut-point, $\mathrm{n}_{\mathrm{c}}$ represents the number of months with rainfall cut-points in excess of $\mathrm{c}$ for each township, and $\lambda_{\mathrm{c}}$ represents the proportion of true positives (PPV) (5). The symbol $\mathrm{n}_{\mathrm{c}} \lambda_{\mathrm{c}}$ represents the number of RRV epidemic months correctly predicted; $\mathrm{n}_{\mathrm{c}}\left(1-\lambda_{\mathrm{c}}\right)$ represents the number of months incorrectly predicted as RRV epidemic months. $\mathrm{N}$ represents the total number of months for the study, and $\lambda$ is the proportion of months that are RRV epidemic months (Smith et al. 1994, Tjitra 2001). The crossover point between sensitivity and specificity creates the threshold, as previously described (Smith et al. 1994, Tjitra 2001). $\chi^{2}$ tests were used to compare outbreak months below and above cut-points for each of the NT townships. Statistical analyses were performed using Intercooled Stata 11.0 (Stata, College Station, TX) and R freeware (R Development Core Team 2010).

\section{Results}

The best-fit logistic regression models are shown for each of the NT townships as determined by Akaike information criterion, with only biologically plausible combinations retained (Table 2). All final models included rainfall, with 1-mo lag, whereas some also contained variables for minimum monthly temperature, average minimum humidity or tide, with various lag times. Darwin urban sensitivity, specificity, and positive predicted value with rainfall cut-point are provided (Fig. 3). The highest cumulative rainfall cutpoint was for Darwin urban at $279 \mathrm{~mm}$, with the lowest for Alice Springs at $41 \mathrm{~mm}$ (Table 2). These results approach average December rainfall as provided by Bureau of Meteorology (Table 3), indicating that some years will require additional larvicidal control in December, whereas most years will require additional January control. These rainfall cut-points have been cross-tabulated against RRV outbreak months for each

\begin{tabular}{|c|c|c|c|c|c|c|c|c|}
\hline $\begin{array}{l}\text { Likelihood } \\
\text { of RRV } \\
\text { outbreak }\end{array}$ & Independent variables & Beta & SE & $p$ & $95 \% \mathrm{CI}$ & AIC & $\begin{array}{c}\text { Sensitivity/ } \\
\text { Specificity } \\
\text { crossover (\%) }\end{array}$ & $\begin{array}{c}\text { Monthly rainfall } \\
\text { cut-points } \\
(\mathrm{mm})\end{array}$ \\
\hline \multirow[t]{3}{*}{ Darwin } & Rainfall (1-mo lag) & 0.005 & 0.001 & $<0.001$ & $0.003-0.009$ & 78.5 & 77 & 279 \\
\hline & $\begin{array}{l}+ \text { Avg min. monthly temp } \\
\quad(3-\text { mo lag })\end{array}$ & 1.28 & 0.30 & $<0.001$ & $0.49-1.6$ & & & \\
\hline & + Max tide (3-mo lag) & -7.83 & 2.31 & 0.001 & $-12.4--3.3$ & & & \\
\hline \multirow[t]{2}{*}{ Jabiru } & Rainfall (1-mo lag) & 0.005 & 0.001 & $<0.001$ & $0.003-0.008$ & 187.3 & 77.7 & 181 \\
\hline & + Max tide & -0.91 & 0.481 & 0.058 & $-1.85--0.032$ & & & \\
\hline \multirow[t]{3}{*}{ Katherine } & Rainfall (1-mo lag) & 0.009 & 0.002 & $<0.001$ & $0.005-0.014$ & 84.7 & 75.8 & 207 \\
\hline & $\begin{array}{l}\text { Avg min. monthly temp } \\
\text { (3-mo lag) }\end{array}$ & 0.772 & 0.263 & 0.003 & $0.26-1.28$ & & & \\
\hline & $\begin{array}{l}\text { Average humidity } \\
\quad \text { (2-mo lag) }\end{array}$ & -0.17 & 0.047 & $<0.001$ & $-0.27--0.08$ & & & \\
\hline \multirow[t]{2}{*}{ Nhulunbuy } & Rainfall (1-mo lag) & 0.004 & 0.001 & 0.003 & $0.002-0.008$ & 103.8 & 78 & 270 \\
\hline & + Max tide (2-mo lag) & -2.66 & 1.44 & 0.65 & $-5.49--0.17$ & & & \\
\hline \multirow{2}{*}{$\begin{array}{r}\text { Tennant } \\
\text { Creek }\end{array}$} & Rainfall (1-mo lag) & 0.01 & 0.003 & 0.001 & $0.005-0.018$ & 44.3 & 88.5 & 74 \\
\hline & $\begin{array}{l}\text { Avg min. monthly humidity } \\
\text { (2-mo lag) }\end{array}$ & 0.11 & 0.037 & 0.001 & $0.045-0.19$ & & & \\
\hline \multirow[t]{2}{*}{ Alice Springs } & Rainfall (1-mo lag) & 0.01 & 0.004 & 0.012 & $0.002-0.019$ & 136.2 & 83 & 41 \\
\hline & $\begin{array}{l}\text { Avg min. monthly temp } \\
\text { (1-mo lag) }\end{array}$ & 0.19 & 0.050 & $<0.001$ & $0.19-0.29$ & & & \\
\hline
\end{tabular}
of the NT townships (Table 4).

Table 2. Logistic regression models with postestimation-generated cumulative rainfall cut-offs for NT townships 


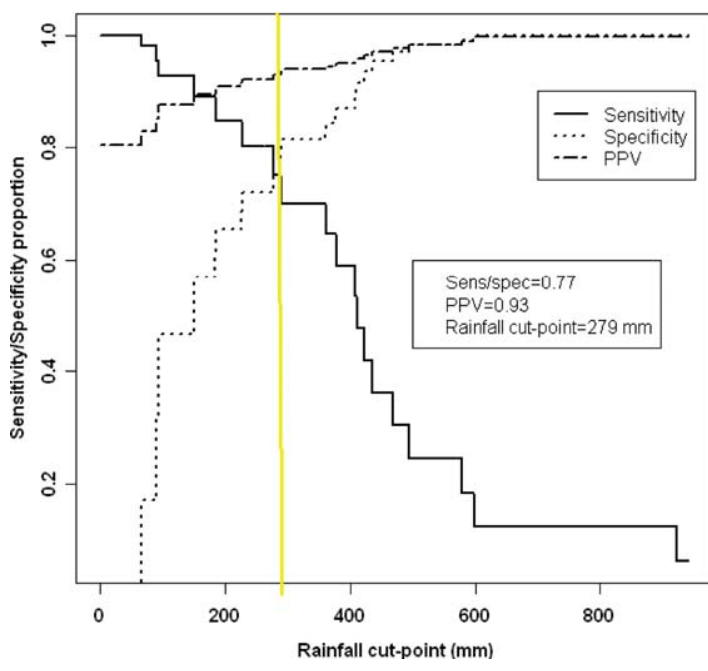

Fig. 3. Sensitivity, specificity, and PPV fraction-RRV outbreak months for Darwin, NT. (Online figure in color.)

\section{Discussion}

We have produced accurate meteorologic-only models for predicting RRV epidemics across the NT. The models differ across NT townships, highlighting the variability of local meteorologic factors influencing RRV epidemics. This is consistent with findings that conditions for RRV disease outbreaks are locally specific and should not be generalized across states or territories (Tong and $\mathrm{Hu}$ 2002, Gatton et al. 2005, Jacups et al. 2008a). Using the postestimations from these models has extended their application to the creation of practical rainfall cut-points that guide Darwin larval control regimes and facilitate timely public health warnings for major NT towns. This is the first time the statistical methods previously used to create malaria parasitemia cut-points have been used to predict epidemics of an arbovirus using meteorological inputs. The cut-points are simple indicators of the cumulative threshold of rainfall required to commence epidemic conditions for December and January, the months in which RRV preepidemic conditions are established.

The start of RRV transmission in Darwin usually coincides with a rise in numbers of Ae. vigilax during

Table 3. Rainfall averages for major NT townships (19412008) (Australian Bureau of Meteorology 2008a) compared with generated monthly rainfall cut-points from Table 2

\begin{tabular}{lcccc}
\hline \hline Township & $\begin{array}{c}\text { Average } \\
\text { annual } \\
\text { rainfall } \\
(\mathrm{mm})\end{array}$ & $\begin{array}{c}\text { Average } \\
\text { Dec. } \\
\text { rainfall } \\
(\mathrm{mm})\end{array}$ & $\begin{array}{c}\text { Average } \\
\text { Jan. } \\
\text { rainfall } \\
(\mathrm{mm})\end{array}$ & $\begin{array}{c}\text { Monthly } \\
\text { rainfall } \\
\text { cut-points } \\
(\mathrm{mm})\end{array}$ \\
\hline Darwin & 1,706 & 246 & 420 & 279 \\
Jabiru & 1,583 & 224 & 356 & 181 \\
Katherine & 1,118 & 211 & 270 & 207 \\
Nhulunbuy & 1,447 & 174 & 284 & 270 \\
Tennant Creek & 452 & 68 & 107 & 74 \\
Alice Springs & 278 & 37 & 35 & 41 \\
\hline
\end{tabular}

${ }^{a}$ Generated cut-points from Table 2.
Table 4. RRV outbreak months for major NT townships (1991-2007)

\begin{tabular}{|c|c|c|c|}
\hline Township & $\begin{array}{l}\text { Months } \\
\text { above } \\
\text { cut-points }\end{array}$ & $\begin{array}{l}\text { Months } \\
\text { below } \\
\text { cut-points }\end{array}$ & $\begin{array}{l}\text { Significance } \\
(p) \chi^{2}\end{array}$ \\
\hline \multicolumn{4}{|l|}{ Darwin } \\
\hline Outbreak month & 13 & 7 & \\
\hline Non-outbreak month & 30 & 154 & $<0.001$ \\
\hline \multicolumn{4}{|l|}{ Jabiru } \\
\hline Outbreak month & 20 & 19 & \\
\hline Non-outbreak month & 45 & 120 & 0.004 \\
\hline \multicolumn{4}{|l|}{ Katherine } \\
\hline Outbreak month & 19 & 8 & \\
\hline Non-outbreak month & 20 & 157 & $<0.001$ \\
\hline \multicolumn{4}{|l|}{ Nhulunbuy } \\
\hline Outbreak month & 8 & 7 & \\
\hline Non-outbreak month & 28 & 161 & $<0.001$ \\
\hline \multicolumn{4}{|l|}{ Tennant Creek } \\
\hline Outbreak month & 6 & 3 & \\
\hline Non-outbreak month & 31 & 164 & $<0.001$ \\
\hline \multicolumn{4}{|l|}{ Alice Springs } \\
\hline Outbreak month & 8 & 20 & \\
\hline Non-outbreak month & 21 & 155 & 0.019 \\
\hline
\end{tabular}

buildup months (September-November), with most transmission taking place in the December to January period when both Ae. vigilax and Cx. annulirostris are present. Presently, ME conducts surveys for saltmarsh mosquito larvae in Darwin's tidally influenced wetlands after high tides $(>7.4 \mathrm{~m})$ and/or $>25 \mathrm{~mm}$ rain (Whelan 2007). Initial rainfall on the wetland occurring at the end of the dry season is quickly absorbed and has little impact on salt-marsh mosquito numbers (Kurucz et al. 2009b). Later rain of 10-25 $\mathrm{mm}$ or more may cause pooling in the drains or wetlands, and result in flooding areas of habitat containing drought-resistant eggs, leading to an increase of adult salt-marsh mosquitoes.

The provision of a cumulative rainfall threshold that is specific for each NT town adjusts for heavy downpours in a short period or small amounts of rainfall over longer periods of time. For the Darwin coastal wetlands, larvae of the salt-marsh mosquito can best be controlled 3-4 d after salt or fresh water inundation (Whelan et al. 1997). Salt-marsh mosquitoes initiate RRV disease outbreaks and also assist in the maintenance of enzootic viral endemicity and transmission, as well as possibly enabling virus survival via droughtresistant eggs over the dry season (Kay 1982, Whelan et al. 1997, Glass 2005). Targeting rainfall also enables timely control of $C x$. annulirostris, the major vector of RRV disease epidemics in the NT later in the wet season (Whelan et al. 1997, Glass 2005, Jacups et al. $2008 \mathrm{~b}$ ). The cumulative rainfall cut-point is a practical management tool that has the capacity to guide $\mathrm{ME}$ larval surveys and enable timely aerial and groundlevel larval control responses (Woodruff et al. 2006), hence reducing labor-intensive larval sampling in Darwin's wetlands. The method may be applicable to other areas where rainfall is an important determinant for RRV epidemics.

Throughout Australia, RRV epidemics have been linked to increases in rainfall, temperature, and the Southern Oscillation Index (Maelzer et al. 1999, 
Woodruff et al. 2002, Kelly-Hope et al. 2004). Although most RRV infections occur in the tropical regions, little has been published on the relation between RRV epidemics and environmental factors in northern Australia (Gatton et al. 2005). Gatton et al. (2005) found that rainfall was the most important predictor of RRV disease epidemics for central and northern regions of Queensland. Additionally, the majority of epidemics in Queensland commenced in January or February, indicating that meteorologic factors leading to RRV disease epidemics occur early in the RRV season, namely December and January. Thus, preconditions of rainfall or other meteorological and environmental variables responsible for commencing the epidemic are of paramount importance in predicting or preventing epidemics (Gatton et al. 2005). Furthermore, extreme weather rainfall events are increasing in frequency as the world's climate changes (Epstein 2002, Intergovernmental Panel on Climate Change 2007), and extreme summer rainfall further increases the likelihood of large RRV disease epidemics (Epstein 2002, Woodruff et al. 2002, Whelan et al. 2003). Our results add to the growing body of data exploring the impact of weather and meteorologic factors on infectious disease (Epstein 2002).

One limitation of this study is the classification of cases based on residential address or post office, as identified on diagnostic blood sample. This address may not reflect the true location of disease acquisition. However, for most cases, this address is the likely location of acquisition (Whelan et al. 1997). The models created high PPVs, and these are best explained by relatively low numbers of false positives, as RRV outbreak months in the NT only occur in wet season months; thus, the Woodruff definition detected fewer outbreak months than would have occurred if environmental variables other than rainfall were strongly at play. In contrast, South Australian RRV epidemics are strongly associated with Murray River height rather than rainfall (Williams et al. 2009).

We recognize that vertebrate hosts play a vital role in the maintenance and amplification of this virus (Russell 1998, Jacups et al. 2008b). Agile wallabies (Macropus agilis) living at East Point Reserve, Darwin, reproduce throughout the year, with greater numbers of large pouch young observed during wet season months (Stirrat 2008). Moreover, there is a peak of RRV naive wallabies emerging from the pouch in December, which coincides with the establishment of outbreak conditions for RRV disease (Stirrat 2008). Our created cut-points for December and January indirectly incorporate vertebrate host data, as the life cycle of the agile wallaby appears to be intricately meshed with the environment of the Australian wetdry tropics (Stirrat 2008).

Whereas this tool is yet to be validated by $\mathrm{ME}$, there are indications of its applicability in the approach to the next RRV disease season. Darwin recently received unseasonal rainfall in September 2010 of $40 \mathrm{~mm}$ (historical average $15.4 \mathrm{~mm}$ ) and October 2010 of $157.8 \mathrm{~mm}$ (historical average $68.7 \mathrm{~mm}$ ) (Australian Bureau of Meteorology 2008b). This rainfall was ac- companied by unusually high tides of $>7.7 \mathrm{~m}$ from August to October, which, combined with this rainfall, resulted in extremely high and sustained numbers of Ae. vigilax over a 6 -wk period that has been unprecedented in >30 yr. The ME responded to the environmental events with routine aerial and ground larval control, but by the end of October there was no outbreak of RRV and, indeed, very few RRV cases reported from the Darwin area. Moreover, agile wallabies (which live in close proximity to Darwin residential areas) have the greatest number of large pouch young during wet season months (December-April), confirming the intricate connection between vertebrate host life cycle, rainfall, and vector numbers. These recent peaks of vectors, in the absence of a subsequent rise in RRV disease cases, indicate that vector numbers alone are not necessarily precursors for RRV outbreaks or epidemics. This is consistent with results in this study that hold December and January as the months in which RRV outbreak conditions are set.

We have produced accurate meteorologic-only models for RRV disease epidemics for each of the major NT towns. Additionally, we have created cumulative rainfall cut-points that provide useful management tools for mosquito control and disease prevention programs. This rainfall threshold has the capacity to reduce the need for expensive helicopter-assisted or ground-based labor-intensive field sampling time. Additionally, these cut-points have superseded predictive models, which require more complex data collection and maintenance, but do not provide timely notification of approaching RRV epidemic conditions. This method may be used to generate meteorological cut-points for other areas in Australia and, indeed, globally for other mosquito-borne diseases.

\section{Acknowledgments}

We thank Peter Markey, Centre for Disease Control, Darwin, for providing RRV disease notifications; Joseph McDonnell from Menzies School of Health Research for statistical advice; and all Medical Entomology staff, past and present, for tirelessly surveying, monitoring, and managing mosquito populations across the Northern Territory. Raelene Whitters is thanked for providing Fig. 1. We also thank Sam Cleland and James Turnbull from the Northern Territory Regional Office, Bureau of Meteorology, who cheerfully provided weather data. This work was supported by an Australian Research Council Linkage Grant and a National Health and Medical Research Council and Sidney Myer Foundation postgraduate scholarship.

\section{References Cited}

Aaskov, J. G., J. Y. Chen, N. T. Hanh, and P. M. Dennington. 1998. Surveillance for Ross River virus infection using blood donors. Am. J. Trop. Med. Hyg. 58: 726-730.

Australian Bureau of Meteorology. 2008a. Australian Bureau of Meteorology Website. (http://www.bom.gov.au).

Australian Bureau of Meteorology. 2008b. Climate Averages for Australian Sites. Australian Bureau of Meteorology, Canberra, Australia. 
Bruzzi, P., S. B. Green, D. P. Byar, L. A. Brinton, and C. Schairer. 1985. Estimating the population attributable risk for multiple risk factors using case-control data. Am. J. Epidemiol. 122: 904-914.

Communicable Diseases Australia. 2006. Notifications of Ross River Virus Infection. Commonwealth Department of Health and Ageing, Canberra, Australia.

Day, J. F., and J. Shaman. 2008. Using hydrologic conditions to forecast the risk of focal and epidemic arboviral transmission in peninsular Florida. J. Med. Entomol. 45: 458465.

Doherty, R. L., H. A. Standfast, R. Domrow, E. J. Wetters, R. H. Whitehead, and J. G. Carley. 1971. Studies of the epidemiology of arthropod-borne virus infections at Mitchell River Mission, Cape York Peninsula, North Queensland. IV. Arbovius infections of mosquitoes and mammals, 1967-1969. Trans. R. Soc. Trop. Med. Hyg. 65: 504-513

Epstein, P. R. 1999. Climate and health. Science 285: 347348.

Epstein, P. R. 2002. Climate change and infectious disease: stormy weather ahead? Epidemiology 13: 373-375.

Flexman, J. P., D. W. Smith, J. S. Mackenzie, J. R. Fraser, S. P. Bass, L. Hueston, M. D. Lindsay, and A. L. Cunningham. 1998. A comparison of the diseases caused by Ross River virus and Barmah Forest virus. Med. J. Aust. 169: 159-163.

Gatton, M. L., B. H. Kay, and P. A. Ryan. 2005. Environmental predictors of Ross River virus disease outbreaks in Queensland, Australia. Am. J. Trop. Med. Hyg. 72: 792-799.

Glass, K. 2005. Ecological mechanisms that promote arbovirus survival: a mathematical model of Ross River virus transmission. Trans. R. Soc. Trop. Med. Hyg. 99: 252-260.

Harley, D., A. Sleigh, and S. Ritchie. 2001. Ross River virus transmission, infection, and disease: a cross-disciplinary review. Clin. Microbiol. Rev. 14: 909-932.

Harley, D., D. Bossingham, D. M. Purdie, N. Pandeya, and A. C. Sleigh. 2002. Ross River virus disease in tropical Queensland: evolution of rheumatic manifestations in an inception cohort followed for six months. Med. J. Aust. 177: 352-355.

Hickie, I., T. Davenport, D. Wakefield, U. Vollmer-Conna, B. Cameron, S. D. Vernon, W. C. Reeves, and A. Lloyd. 2006. Post-infective and chronic fatigue syndromes precipitated by viral and non-viral pathogens: prospective cohort study. Br. Med. J. 333: 575 .

Intergovernmental Panel on Climate Change. 2007. Climate Change 2007: The Physical Science Basis; Summary for Policy Makers. Intergovernmental Panel on Climate Change, Geneva, Switzerland.

Jacups, S. P., P. I. Whelan, and B. J. Currie. 2008a. Ross River virus and Barmah Forest virus infections: a review of history, ecology, and predictive models, with implications for tropical northern Australia. Vector Borne Zoonotic Dis. 8: 283-298.

Jacups, S. P., P. I. Whelan, P. G. Markey, S. J. Cleland, G. J. Williamson, and B. J. Currie. 2008b. Predictive indicators for Ross River virus infection in the Darwin area of tropical northern Australia, using long-term mosquito trapping data. Trop. Med. Int. Health 13: 943-952.

Kay, B. H. 1982. Three modes of transmission of Ross River virus by Aedes vigilax (Skuse). Aust. J. Exp. Biol. Med. Sci. 60: 339-344.

Kay, B. H., I. D. Fanning, and J. G. Carley. 1982. Vector competence of Culex pipiens quinquefasciatus for Murray Valley encephalitis, Kunjin, and Ross River viruses from Australia. Am. J. Trop. Med. Hyg. 31: 844-848.

Kelly-Hope, L. A., D. M. Purdie, and B. H. Kay. 2004. Ross River virus disease in Australia, 1886-1998, with analysis of risk factors associated with outbreaks. J. Med. Entomol. 41: 133-150.

Kurucz, N., P. I. Whelan, J. M. Carter, and S. P. Jacups. 2009a. A geospacial evaluation of Aedes vigilax larval control efforts across a coastal wetland, Northern Territory, Australia. J. Vector Ecol. 34: 317-323.

Kurucz, N., P. I. Whelan, J. Carter, and S. P. Jacups. 2009 b. Vegetation parameters as indicators for salt marsh mosquito larval control in coastal swamps in northern Australia. Arbo Res. Aust. 10: 84-90.

Lindsay, M. D., A. K. Broom, A. E. Wright, C. A. Johansen, and J. S. Mackenzie. 1993. Ross River virus isolations from mosquitoes in arid regions of Western Australia: implication of vertical transmission as a means of persistence of the virus. Am. J. Trop. Med. Hyg. 49: 686-696.

Lindsay, M., C. Johansen, A. K. Broom, D. W. Smith, and J. S. Mackenzie. 1995. Emergence of Barmah Forest virus in Western Australia. Emerg. Infect. Dis. 1: 22-26.

Linthicum, K. J., A. Anyamba, C. J. Tucker, P. W. Kelley, M. F. Myers, and C. J. Peters. 1999. Climate and satellite indicators to forecast Rift Valley fever epidemics in Kenya. Science 285: 397-400.

Mackenzie, J. S., A. K. Broom, R. A. Hall, C. A. Johansen, M. D. Lindsay, D. A. Phillips, S. A. Ritchie, R. C. Russell, and D. W. Smith. 1998. Arboviruses in the Australian region, 1990 to 1998. Commun. Dis. Intell. 22: 93-100.

Maelzer, D., S. Hales, P. Weinstein, M. Zalucki, and A. Woodward. 1999. El Nino and arboviral disease prediction. Environ. Health Perspect. 107: 817-818.

Queensland Institute of Medical Research. 2010. VectorBorne Disease Early Detection and Surveillance (VEDS) System. Queensland Institute of Medical Research, Brisbane, Australia.

R Development Core Team. 2010. R: A Language and Environment for Statistical Computing. R Foundation for Statistical Computing, Vienna, Austria.

Rohe, D. L., and R. P. Fall. 1979. A miniature battery powered $\mathrm{CO}_{2}$ baited light trap for mosquito borne encephalitis surveillance. Bull. Soc. Vector Ecol. 4: 24-27.

Russell, R. C. 1994. Ross River virus: disease trends and vector ecology in Australia. Bull. Soc. Vector Ecol. 19: 73-81.

Russell, R. C. 1998. Mosquito-borne arboviruses in Australia: the current scene and implications of climate change for human health. Int. J. Parasitol. 28: 955-969.

Russell, R. C. 2002. Ross River virus: ecology and distribution. Annu. Rev. Entomol. 47: 1-31.

Smith, T., J. A. Schellenberg, and R. Hayes. 1994. Attributable fraction estimates and case definitions for malaria in endemic areas. Stat. Med. 13: 2345-2358.

Stirrat, S. C. 2008. Age structure, mortality and breeding in a population of agile wallabies (Macropus agilis). Aust. J. Zool. 56: 431-439.

Tjitra, E. 2001. Improving the Diagnosis and Treatment of Malaria in Eastern Indonesia. Faculty of Science, Information Technology \& Education, Northern Territory University, Darwin, Australia.

Tong, S., and W. Hu. 2001. Climate variation and incidence of Ross River virus in Cairns, Australia: a time-series analysis. Environ. Health Perspect. 109: 1271-1273.

Tong, S., and W.Hu. 2002. Different responses of Ross River virus to climate variability between coastline and inland cities in Queensland, Australia. Occup. Environ. Med. 59: 739-744.

Whelan, P. I. 1987. Mosquito vector control in the Northern Territory. Bull. Mos. Control Assoc. Aust. 1: 32- 47.

Whelan, P. I. 1989. Integrated mosquito control in Darwin. Arbo Res. Aust. 5: 178-185. 
Whelan, P. I. 2007. Mosquito vector control in the Northern Territory. Northern Territory Communicable Diseases Bulletin 14: 12-18.

Whelan, P. I., A. Merianos, and G. Hayes. 1997. Ross River virus transmission in Darwin Northern Territory, Australia. Arbo Res. Aust. 7: 337-345.

Whelan, P. I., S. P. Jacups, L. Melville, A. Broom, B. J. Currie, B. Brogan, F. Smith, and P. Porigneaux. 2003. Rainfall and vector mosquito numbers as risk indicators for mosquito-borne disease in central Australia. Commun. Dis. Intell. 27: 110-116.

Whelan, P. I., N. Kurucz, A. Warchot, J. Carter, W. Pettit, M. Shortus, H. Nguyen, S. Anderson, N. Copley, R. Whitters, and T. Pearce. 2006. Medical Entomology Branch Report 2005/6. Northern Territory Government-Department of Health and Community Services, Darwin, Australia.
Williams, C. R., S. R. Fricker, and M. J. Kokkinn. 2007. RRForcaster computer program, version 1.1. Williams, Fricker, and Kokkinn, Adelaide, Australia.

Williams, C. R., S. R. Fricker, and M. J. Kokkinn. 2009. Environmental and entomological factors determining Ross River virus activity in the River Murray Valley of South Australia. Aust. N.Z.J. Public Health 33: 284-288.

Woodruff, R. E., C. S. Guest, M. G. Garner, N. Becker, J. Lindesay, T. Carvan, and K. Ebi. 2002. Predicting Ross River virus epidemics from regional weather data. Epidemiology 13: 384-393.

Woodruff, R. E., C. S. Guest, M. G. Garner, N. Becker, and M. Lindsay. 2006. Early warning of Ross River virus epidemics: combining surveillance data on climate and mosquitoes. Epidemiology 17: 569-575.

Received 10 August 2010; accepted 28 November 2010. 